\title{
The Hard Lessons Learned by the COVID-19 Epidemic in Italy: Rethinking the Role of the National Health Care Service?
}

\author{
Philippe Primo Caimmi ${ }^{1, *}$, Andrea Capponi ${ }^{1}$, Fabrizio Leigheb ${ }^{1}$, Franca Dall' Occo ${ }^{1}$, Roberto Sacco $^{1}$, Mario Minola ${ }^{1}$, \\ Emmanouil Ioannis Kapetanakis ${ }^{2,(D)}$ \\ ${ }^{1}$ Medical Directorate, University Hospital of Novara, Corso Mazzini 18, Novara 28100, Italy \\ ${ }^{2}$ Department of Intensive Care (I.C.U.) \& Covid-19 Care Unit, "Tzaneio" General Hospital of Piraeus, Zanni \& Afentouli Avenue, Piraeus, 18536, Greece
}

\section{ARTICLE INFO}

Article History

Received 07 January 2021 Accepted 13 March 2021

\section{Keywords}

COVID-19

SARS-Cov-2

Pandemic

National Health Care System

\begin{abstract}
The dramatic events precipitated by the Severe Acute Respiratory Syndrome Coronavirus 2 (SARS-CoV-2) virus pandemic have highlighted the limitations and contradictions of our country's current health care delivery model plagued by the closure of healthcare delivery structures, staff reductions, privatizations and inadequate funding which have been affecting the Italian National Health System during the past 10 years. The COVID-19 epidemic has a hefty bill: thousands of deaths - mainly elderly, hospitals overwhelmed, residential assistance structures reaching their limits, sick people left alone and uncared in homes, the disruption in life habits and an altered daily way of living never experienced before; all have contributed into making the ongoing tragedy even more painful. Herewith, we present and discuss the information and reflections from our experiences and postulate the rethinking of the established socio-health policies not only in Italy but also in other western countries which have failed to curtail the epidemic via conventional management approaches.
\end{abstract}

(C) 2021 The Authors. Published by Atlantis Press International B.V. This is an open access article distributed under the CC BY-NC 4.0 license (http://creativecommons.org/licenses/by-nc/4.0/).

\section{INTRODUCTION}

Severe Acute Respiratory Syndrome Coronavirus 2 (SARS-CoV-2) is quite a new and novel virus to physicians and to the world. The precise mechanics of infection, its clinical presentation, epidemiology, treatment and consequences post infection are still under continuous investigation with much remaining unclear [1]. Consequently, COVID-19's effect has been devastating in many countries independently to them been economically rich or poor, developed or underdeveloped, with democratic or non democratic governments and having a public or private-based National Healthcare System (NHS). Accordingly, everyone can observe daily the existence of multiple speculations and contradictions amongst physicians and scientists, politicians, economist and others in the matter of decision making in the management of the infection and in setting priorities about social restrictions and resource utilization. These assertions support the postulation that something is wrong in the current management of the infection worldwide. In this report we present and analyze what has happened recently in Italy during the COVID-19 outbreak as this was the first western country to be seriously affected from the epidemic and how an overstretched and underfunded system failed to adequately respond to the epidemic.

\subsection{Why First, Why So Profound? Analysis of the Pandemic Diffusion in Italy}

The epidemic started officially in Italy in the second half of February 2020, about 3 months after it began in China. Italy was the first

Corresponding author.Email: philippe.caimmi@maggioreosp.novara.it western country to be affected by the COVID-19 epidemic. There are many reasons to explain why Italy was affected first and more heavily than other European countries. During the previous years China invested significant recourses to create a support infrastructure and improve commercial connections and trade routes with Europe. Italy has been committed more than ever to been a bridge to far eastern and Asian countries. Therefore, this Chinese program of investment and commerce co-operation has been termed "the New Silk Road" as a reference to the trade route established by Marco Polo and other Venetian merchants in the 13th century AD (Figure 1).

Hubei province, the epicenter of the pandemic, is one of China's most important commercial areas for the Italian economy. Wuhan, capital of Hubei province, is also called the "Detroit of China" and Italy, as a principal global producer of car parts and mechanical components, has many production sites and export collaborations located in Hubei. The direction of dissemination of the epidemic to Europe seems to have followed exactly this "Silk Road" via a network of countries through China, Korea, Vietnam, India, Iran and Greece to Italy [2]. At the same time the main centers of the epidemic (Figure 2) in Italy correspond with areas where the concentration of Chinese economic interest is the strongest. In fact $65 \%$ of all Chinese investments in Italy are concentrated in the four areas in the north of Italy: Lombardy, Piedmont, Emilia-Romagna and Veneto which have been affected the most by the COVID-19 epidemic (Figure 2). This distribution of infection corresponds to the distribution of Chinese residents living in Italy. So it is obvious that commercial activities such as the exchange of people/workers (Italian and Chinese) and products between Italy and China contributed to the dissemination of the virus between the two 


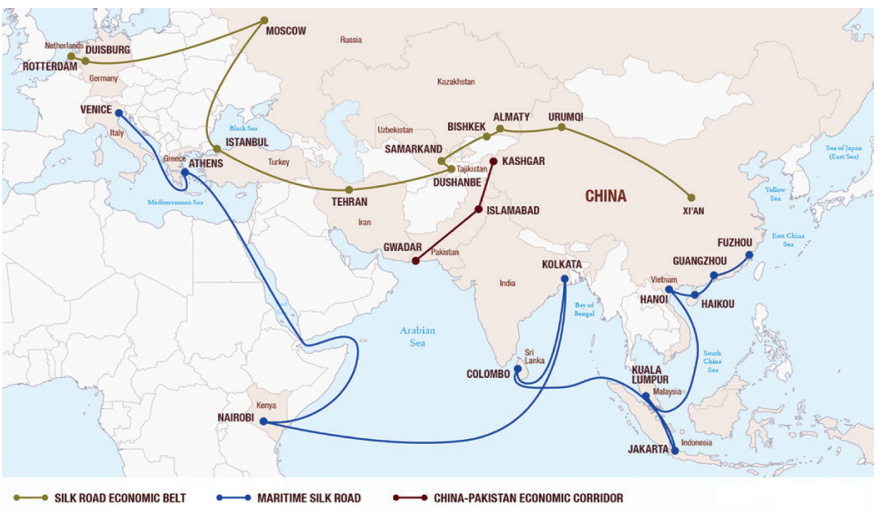

Figure 1 Chinese program of investment and commercial trade routes titled "New Silk Road" in reference to the trade route established by Marco Polo and other Venetian merchants in the 13th century AD. Source: James McBride, Building the New Silk Road. Council of Foreign Relations, 2015. Available at: https://www.cfr.org/backgrounder/buildingnew-silk-road [Internet] (Image used with creative commons copyright permission).

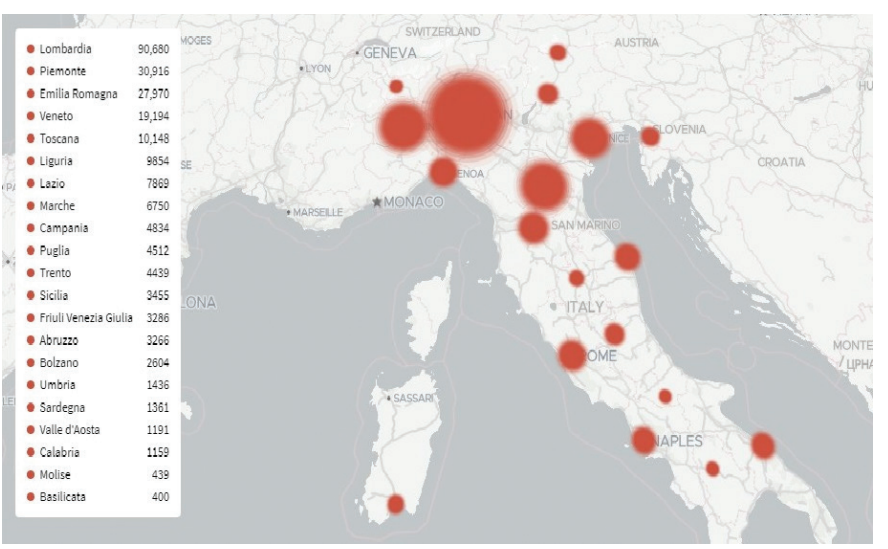

Figure 2 Distribution of COVID-19 cases in Italy on the 10th of June 2020. Source: Gedi Visual. Available at: https://lab.gedidigital.it/gedivisual/2020/coronavirus-in-italia/ [Internet] (Image in the public domain and under fair use policy).

countries [3]. Considering the discontinuation by the Italian government of direct flights and the control of Chinese passenger travel, we believe that the spread of the virus in Italy occurred mainly by European citizens who arrived from China on indirect flights. As a matter of fact, when the Chinese lock down started most of the Italian companies decided to temporarily suspend their activities in China recalling back their workers to Italy so as to reduce wages and company expenses. This action was decided and performed by Italian corporations independently and outside the control of the Italian central government. The Lombardy region has three major airports (Bergamo, Linate and Malpensa) with excellent worldwide connections as well as continental and indirect flights. Not surprisingly, these airports correspond accordingly to areas of the country affected most by the epidemic [4].

In addition to these mechanisms of spread of the outbreak in Italy, it is important to consider the demographic characteristics of the Italian population. Italy has one of the oldest populations and lowest birth rate in the world. Over time there has been a continuous increasing of the percentage of the elderly in the general population, with Italy having achieved one of the greatest overall longevity. At the moment people over 65 years of age constitute $22.8 \%$ of the populace [5]. However, the Italian elderly population presents a lower freedom from chronic diseases in comparison with other countries with similar life expectancy [6]. Therefore, the country has a very significant proportion of its elderly population presenting with a high incidence of chronic morbidity [6]. This high morbidity percentage is the result of the shifting of recourses from preventive medicine to a hospital-based centralization of health care. This demography is a principal reason of the high diffusion and especially the high mortality of the epidemic in Italy.

There has been the suggestion that the introduction of the virus in Italy had started before December 2019 [7]. However the explosion of the epidemic actually occurred at the end of January 2020, about 20 days after the end of the Christmas holidays. During that period most of the Italians returned back to their parental homes with their families, while in the same period students were at home because of the winter/Christmas holidays (December 20-January 7). Throughout this period there was a significant people movement for holiday shopping, winter tourism and for visiting friends and/ or relatives allowing for the virus to spread. In addition to this, the weather during that period was relatively mild thus promoting movement and intermingling amongst the population consequently increasing viral dissemination [8].

\subsection{Reasons for Underestimating the Pandemic Risk in Italy}

The SARS-Cov-2 Corona virus is the second pandemic of this century, which occurred 11 years after the pandemic flu, now incorrectly been called "swine flu", of 2009 which was caused by the A H1N1 virus. Comparably to SARS (2002-2004) and afterward with the Middle East Respiratory Syndrome (MERS) (2013) the relatively limited diffusion and worldwide impact of the swine flu compared to the exaggerated reaction elicited by governments and health authorities, such as the considerable investment in vaccines which were produced in significantly larger quantities than needed, have generated a general indifference and even distrust against the World Health Organization (WHO), global media and even scientists in general within the populations but also in governments of western countries $[9,10]$. Consequently, despite the initial reports coming from China, the threat of the new SARS-Cov-2 virus was greatly underestimated not only by the public but also by governments, local health authorities and even the WHO.

\subsection{Weaknesses in Resources and Infrastructure in the Italian NHS}

As a consequence of the global economic crisis and the European Community's rigid fiscal control policies, Italy had to reduce healthcare expenditures by decreasing the number of beds per 1000 habitants, reducing the number of public insurance compensated days for in-hospital stay, regulating staff replacement and appointments by implementing a three retired for each new member of hospital staff (3:1) hiring policy, freezing the re-valuing and inflation adjustment of staff contracts and salaries and reducing 
the allocated funds for preventive medicine and primary care. Consequently in 2017, which is the latest year that data are available, hospital beds were reduced to 191,000, almost a third of the number two decades earlier, in a country which in the meantime was essentially growing older. Specifically, while in 1998 there were 5.8 beds per thousand inhabitants; in 2017 the number was only 3.7 beds [11,12]. According to medical unions, 46,000 of needed healthcare staff is missing from the Italian health system, including 8,000 doctors. It should also be noted that the hiring freeze (one of the measures imposed as part of the various fiscal controls established in 2009) has contributed into making Italian doctors amongst the oldest in Europe (over half of them are over 55 years of age). Furthermore, the restrictions of access to medical school and post-graduate training, the suspension of the contractual inflation adjustment of staff salaries and the limitations imposed for engaging in private practice for NHS doctors have also affected morale, recruitment and retention [13].

Quite significantly, much of the available infrastructure is old or getting obsolete. A national survey on the state of hospital real estate assets conducted by the Ministry of Health [14], demonstrated among other things that $26 \%$ of Italian hospitals are housed in historical buildings originally intended for other functions, for example monasteries which also served as infirmaries as far back as the Middle Ages. Thus many hospitals are not modern nor based on purposely designed and build structures. The most widespread building typology is that of the block type (39\%), followed by the pavilion type (22\%) both of which are outdated designs. Only $25 \%$ of the hospitals had been refurbished by the time of the census. The average age of the buildings is 62 years and more than half of the hospitals were built before the 1940s. Amongst the various improvements envisioned by the proposed Extraordinary Investment Program, a government health infrastructure modernization initiative, hospital structural improvements was allocated the largest percentage of available funding (89\%) compared to those relating to other types of healthcare structures, such as residential assistance structures (6\%) and primary care buildings (5\%).

\subsection{Limitations of Response Models}

The current Italian generation of professionals in the health care sector was cultivated during a previous age in which such a great epidemic had never happened in the country. Even the Italian civil protection organization has never managed a major epidemic, but only environmental catastrophes. Only the army has specific know-how, training and associated infrastructure relating to this type of event within their nuclear, biological and chemical defense doctrine, but the Italian government has unfortunately used the army only marginally in the management of the epidemic. Therefore, response models amongst different regions were actually variable depending on expertise, organization and available infrastructure.

In terms of organizational response, the Instant Report, a government conducted pandemic survey, demonstrated that three regional-based response models to the pandemic have actually emerged [15]:

1. A predominantly hospital-based management model, used in the Lombardy region.

2. A predominantly out of hospital-based management model, which is utilized in the Veneto region.

3. A combined hospital - out of hospital-based management model, used in the Emilia-Romagna region.

Analyzing by matching the response models with data collected in the first month of the epidemic in Italy (20 February-20 March, 2020) by the Instant Report and by regional registries for healthcare expenditures [14], it is was demonstrated that the worst performing was the hospital-based model which presented the highest incidence of hospitalization, the highest increase in intensive care unit (ICU) occupancy and the highest percentage of mechanically ventilated patients. Also, the predominantly hospital-based management model has the highest incidence of COVID-19 infection amongst healthcare staff, the lowest percentage of COVID-19 tested population and most importantly much more overall mortality than the other models (Table 1).

It is evident that the existence of such a significant variability in response models amongst the Italian healthcare regions, which are under the control of their provincial (Italy is comprised of 20 regional authorities) and not the central government made much more difficult the implementation of a prompt and well organized national management response to such an unprecedented epidemic.

\section{DISCUSSION}

Concentration on the economic impact, an initial underestimation and misunderstanding of the epidemic, chronic structural weaknesses of the NHS caused by reductions in resources, the predominant utilization of a hospital-centered management model, problems in the chain of command and lack of experience in the management of large epidemics are the contributing factors for over 30,000 deaths in the first 60 days of the COVID-19 epidemic in Italy. Therefore, we must now rethink and regroup fast, developing a new and improved organizational model of the Italian NHS to manage the infection and also for the future. Learning from this

Table 1 Percentage variation in general mortality by age group between March 2019 and 2020 classified by regional response model

\begin{tabular}{lcccccc}
\hline Age groups (years) & $\mathbf{0 - 1 4}(\mathbf{\%})$ & $\mathbf{1 5 - 6 4}(\mathbf{\%})$ & $\mathbf{6 5 - 7 4}(\mathbf{\%})$ & $\mathbf{7 5 + ( \% )}$ & Total (\%) & COVID-19 response model \\
\hline Lombardy & 16.3 & 32.0 & 68.9 & 54.9 & 54.4 & Mainly hospital management \\
Veneto & -63.2 & 10.3 & 10.7 & 14.7 & 13.6 & Out of hospital management \\
Emilia-Romagna & -43.3 & 31.0 & 49.4 & 26.4 & 29.0 & $\begin{array}{c}\text { Combined hospital - out of } \\
\text { hospital management }\end{array}$ \\
\hline
\end{tabular}


experience we feel that there are a number of possible improvements that can be pursued. Specifically:

\subsection{Innovations on Healthcare Constructions}

In the Italian context, research and innovations in the field of hospital architecture is lacking. Current architectural models and layouts for inpatient areas are unimaginative and out-of-date. Moreover, the recent government's regulatory edict for the provision of $10 \%$ (out of the total number), of individual occupancy rooms in hospitals is inadequate and underestimated both in terms of current but also past patient management needs [16]. The epidemic more than ever demonstrated how inadequate this number actually is, considering the increased need for patient isolation but also considering the nowadays widespread demand by the patients for privacy and quality of the environment in the hospitalization areas [17].

Specifically, the single hospital room represents the most suitable configuration to contain the spread of aerial infections. In fact, it is possible to design and install systems for the independent and dedicated regulation of microclimatic and environmental conditions in the single room configuration, adaptable to the clinical and medical needs of the individual patient hospitalized. In addition it can be possible to manage independently the conditions of filtering, air volume/hour exchange and pressure, in order to keep a chamber in overpressure or under pressure with respect to the adjacent rooms or the corridor. The single patient room also has numerous advantages over contact infections, since it allows more frequent, easier and more complete cleaning and disinfection practices. The disinfection procedure of the single hospital rooms can be carried out completely at each discharge, as opposed to what occurs in the multi-bed rooms. In multi-bed rooms antibacterial and self-cleaning materials and a configuration of space and furnishings to minimize the areas that are difficult to clean and accumulate contaminants are needed to support the easy and effective cleaning of these rooms.

Modular architecture, i.e. assembling prefabricated parts to create buildings ready for use, has a very strong eco-sustainable character. In fact, it significantly reduces the environmental impact caused by construction sites, minimizing the necessary energy expenditure needed to build large structures. It also allows speeding up the rate of construction compared to classical building methods and can be quite applicable in a pandemic situation where rapid hospital space expansion is needed [18].

\subsection{Strengthening Out of Hospital Care}

The instant report demonstrates clearly that isolation of infective people remains the primary strategy [15]. The mainly out of hospital management model allows the isolation locally of patient while the mainly hospital-based management model makes much easier the diffusion of the epidemic because of the transportation and concentration of symptomatic not screened patients in general hospitals and not in specific COVID-19 hospitals. The out of hospital model uses testing essentially for screening the asymptomatic infective people and to isolate positive cases to prevent the diffusion of the SARS-Cov-2 infection. In contrast, the hospital model uses testing essentially as a diagnostic confirmation in symptomatic hospitalized patients. In hospital testing is used to isolate admitted patients into COVID-19 dedicated wards however, it has the drawback of a 24-48 h delay (time required by the lab). This approach disrupts the in hospital COVID-19 spread but has little impact on the general population and in containing the pandemic. So as a result it produced a catastrophic rush of patients requiring access to hospitals and to advanced care. It is becoming obvious that in outbreaks such as the COVID-19 epidemic which have an exceptional high diffusion pattern, the hospital-based response model, as the one used in Lombardy, is not able to contain and control the epidemic (Table 1).

An innovative adjunct in out of hospital medical care could be that of "digital/tele-medicine". In the subsequent management of the epidemic, all the regions should give focus on a "digital/telemedicine" strategy to strengthen the home monitoring of positive and non-positive patients and to map the movements of the population in their territory. The application of such technologies however raises technical, social and legal challenges but it could definitively help support the relaxation of some of the current restrictions until the adequate availability of the vaccine or an effective treatment for SARS-Cov-2 is developed.

\subsection{Improve Health Care Staff Characteristics}

A new policy to improve human resources in the system is as important as infrastructural investment and upgrades. This policy has to give more value into building staff proficiency by means of developing a more attractive career profile for young physicians and nurses with incentives for training, developing skills and expertise acquisition, implementing assessment of competence and performance and fostering leadership and innovation. Naturally, to encourage staff to develop those characteristics their receiving benefits and compensation must be adequate and co-measurable.

\section{CONCLUSION}

The dramatic events precipitated by the SARS-Cov-2 virus epidemic have highlighted the limitations and contradictions of the Italian health care model which was already suffering from the closure of structures, staff reductions, privatizations and inadequate funding. The pandemic leaves behind a heavy toll: thousands of deaths among the elderly, hospital services overwhelmed and clogged up, a disruption of everyday life and economic activity, but even more a feeling of uncertainty and despair. Reflecting on all these we suggest in this report that we have to rethink and re-organize the socio-health policies in Italy but also in other western countries with similar health care provision mentality. The COVID-19 epidemic exposed precisely all of the shortcomings of a "top heavy" hospital-based care system. The crisis highlighted the poverty of our out of hospital resources, the lack of integration between social and socio-health services, the misguided focus on specialized and hospital-based interventions and the depreciation and neglect of out of hospital medicine. Our final thought is that of the famous Italian proverb "Sbagliando s'impara" which means one must learn from his mistakes in hopes our message becomes heard! 


\section{CONFLICTS OF INTEREST}

The authors declare they have no conflicts of interest.

\section{AUTHORS' CONTRIBUTION}

All authors participated and contributed to a degree meriting authorship in most key parts of the drafting of this manuscript. All authors have reviewed the final version of the manuscript and have approved it.

\section{REFERENCES}

[1] Wu Z, McGoogan JM. Characteristics of and important lessons from the coronavirus disease 2019 (COVID-19) outbreak in China: summary of a report of 72314 cases from the Chinese Center for Disease Control and Prevention. JAMA 2020;323;1239-42.

[2] OECD. The Belt and Road Initiative in the global trade, investment and finance landscape. In: OECD Business and Finance Outlook 2018. Paris: OECD Publishing; 2018.

[3] Instituto Nazionale di Statistica (ISTAT). Salute e Sanita. Available from: https://www.istat.it/it/archivio/covid-19 [Internet].

[4] Dati di Traffico - Ente Nazionale Aviazione Civile (ENAC) Edito dalla Direzione Sviluppo Studi Economici e Tariffe. 2018. Available from: https:/www.enac.gov.it/sites/default/files/ allegati/2019-giu/dati_di_traffico_2018.pdf.

[5] Eurostat. Statistics explained: population structure and ageing. Available from: https://ec.europa.eu/eurostat/statistics-explained/ index.php?title=Population_structure_and_ageing\#Median_ age_is_highest_in_Italy [Internet].

[6] GBD 2017 Italy Collaborators. Italy's health performance, 19902017: findings from the Global Burden of Disease Study 2017. Lancet Public Health 2019;4;e645-e57.

[7] Apolone G, Montomoli E, Manenti A, Boeri M, Sabia F, Hyseni I, et al. Unexpected detection of SARS-CoV-2 antibodies in the prepandemic period in Italy. Tumori 2020;300891620974755.

[8] Copernicus. Europe's eyes on earth: the weather in December 2020. Available from: https://surfobs.climate.copernicus.eu/ stateoftheclimate/december2020.php [Internet].

[9] European Commission, Directorate General Health and Consumer Protection. Special Eurobarometer 257. 2006. Available from: https://ec.europa.eu/health/ph_threats/com/ Influenza/flu_specialeurobarometer.pdf.
[10] European Commission, Directorate General Regional and Urban Policy. European Regional Development Fund and Cohesion Fund, Concepts and Recommendations - Monitoring and Evaluation in the practice of European Cohesion Policy 2014 - 2020. 2014. Available from: https://ec.europa.eu/regional_policy/sources/ docgener/informat/2014/guidance_monitoring_evaluation_ en.pdf.

[11] Instituto Nazionale di Statistica (ISTAT). STATBASE: L'Accesso Ai Principali Dati. Available from: http://dati.istat.it/viewhtml. a spx?il=blank \&vh $=0000 \& v f=0 \& v c q=1100 \& \mathrm{graph}=0 \&$ viewmetadata $=1 \&$ lang=it\&QueryId=34540 [Internet]

[12] Ministero della Salute. Relazione Generale sulla situazione economica del Paese 2011 - Il Servizio Sanitario Nationale. Available from: http://www.salute.gov.it/portale/documentazione/p6_2_2_ 1.jsp?lingua=italiano\&id=1780 [Internet].

[13] Ministero della Salute, Direzione Generale della Programmazione Sanitaria. Nucleo di Valutazione e Verifica degli Investimenti Pubblici. Programma Straordinario di Investimenti in edilizia e tecnologie sanitarie. Valutazione ex post. Gli Investimenti in Sanità nell'Agenda per lo Sviluppo del Paese. $1^{\circ}$ Report. 2013. Available from: http://www.salute.gov.it/imgs/C_17_pubblicazioni_2055_ allegato.pdf.

[14] Ministero dell'Economia e delle Finanze, Dipartimento della Ragioneria Generale dello Stato. Le Tendenze di medio-lungo periodo del sistema pensionistico e socio-sanitario. Rapporto n. 13 - Nota di aggiornamento 2012. September 2012. Available from: https://www.sanita24.ilsole24ore.com/pdf2010/Sanita2/_ Oggetti_Correlati/Documenti/Regioni-e-Aziende/RGS\%20 Le-tendenze\%20Rapporto_n.13.pdf?uuid=Ab5e4tyF [Internet].

[15] Università Cattolica di Roma del Sacro Cuore, Alta Scuola di Economia e Management dei Sistemi Sanitari (ALTEMS). $5^{\circ}$ Instant Report COVID-19 (dati aggiornati al 28.04.2020). In: Analisi dei modelli organizzativi di risposta al Covid-19. Rome; 2020. pp. 147-78. Available from: https://issuu.com/marziagallo/ docs/instant_fase1_finito_3072020[Internet].

[16] Chaudhury H, Mahmood A, Valente M. Advantages and disadvantages of single-versus multiple-occupancy rooms in acute care environments: a review and analysis of the literature. Environ Behav 2005;37;760-86.

[17] Steinberg JP, Denham ME, Zimring C, Kasali A, Hall KK, Jacob JT. The role of the hospital environment in the prevention of healthcare-associated infections by contact transmission. HERD 2013;7;46-73.

[18] Zhou Y, Zhang Z, Wang B, Ren G, Qi H, Wang X. Construction time, cost and testing data of a prefabricated isolation medical unit for COVID-19. Data Brief 2020;32;106068. 